\title{
The Design and Implementation of the Virtual National Costumes Museum Based on VRP
}

\author{
Zichen Meng ${ }^{1, a}$, Yaxia Liu ${ }^{1, b^{*}}$ Hongyun Xiong ${ }^{2, c}$ \\ ${ }^{1}$ The School of Information Engineering, Beijing Institute of Fashion Technology,Beijing \\ 100029, China \\ ${ }^{2}$ The Academy of Art\&Design, Beijing Institute of Fashion Technology,Beijing 100029,China \\ aemail: 379539053@qq.com, bemail:gxylyx@bift.edu.cn, cemail:xhy68@sohu.com
}

\begin{abstract}
Keywords: Virtual Reality, National Costumes Museum, 3ds Max, VRP, Sketchup
Abstract. Virtual museum is a virtual display of the traditional physical museum through 3D modeling and virtual reality technology. In this paper, the National Costume Museum of Beijing Institute Of Fashion Technology is used as the background, the Google Corporation SketchUp software is used to model, then the model is imported into 3ds Max, and the lighting is rendered, the virtual reality software VRP is used to make the system. The virtual museum is created and it release the restriction of the physical museum in time and space.
\end{abstract}

\section{Introduction}

Virtual museum is also called the digital museum, it is the application which can form of scene simulation. The audience in this kind of virtual museum can undertake free roaming and also can be interactive operation. Virtual museum is dependent on 3ds Max and virtual reality platform (VRP) software.

The content of this design is to create a virtual museum. The visitors can walk free in it, watch collections of the Museum of the 3D model, and can rotate 360 degrees of the product. The functions of the physical museum can maximize as much as possible. In this paper, the design target is located in the national costume museum, Beijing Institute of clothing technology, which has a collection of a large number of ancient costumes of ethnic and minority dress, and have a strong visual presentation and historical reference value.

VR technology is a new integrated information technology emerged since the end of the twentieth century. It is a blend of multiple branch of information technology and the application field is wide. The national costume museum belongs to Beijing institute of fashion Technology. It has China's 56 ethnic clothing, accessories, fabric, batik, embroidery and other traditional national costume products .There are more than ten thousand pieces, which are plenty of collections of ancient national costumes and ethnic costumes, these exquisite dress are the Oriental cultural treasures. They have a strong ability of visual display and historical reference value. Based on the National costume museum, Google SketchUp software was used to model the museum, then the model is imported into 3ds Max (3 d Studio Max) to merge, lighting rendering. Virtual Reality software VRP (Virtual Reality Platform) was used for roaming. Virtual museum can promote the national museum industry more quickly into the information age, no longer restricted by time and place. It can realize intelligent, science and technology. The cultural relics, history, culture and art can be showed vividly. We need not change the environment of the collection. We can ensure the safety of the collection of cultural relic's .At the same time the function of the museums is also maximum extended ${ }^{[1]}$.

\section{The production process of virtual museum of national costumes}

The figure below shows the flow chart of system design, first of all, the national costume museum exhibits should be collected and digitized. The different angles for the same costume exhibits were got. Digitization makes it easy to use for the next step, then use Google sketchup software to establish the 
national costume museum model, then the grain is imported and the roaming animation effects were formed. Then put these data into 3ds Max software to render and bake. Finally, the 3ds Max data are imported into the virtual reality software VRP. Figure 1 shows the flow chart of system design.

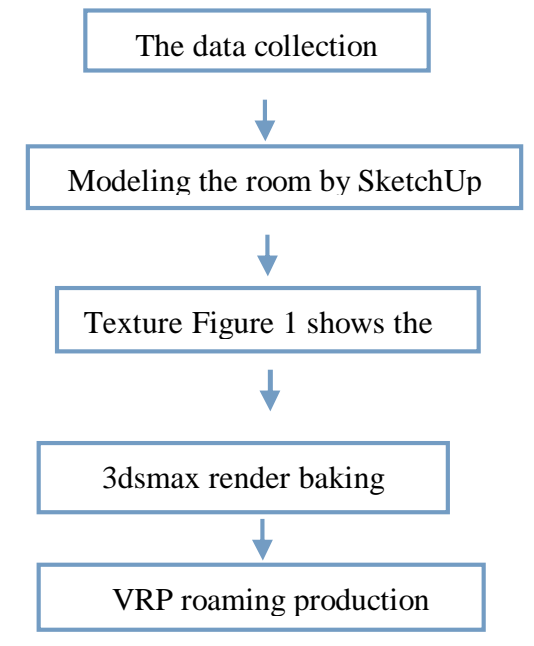

Fig 1. The flow chart of system design

\section{The collection of National dress image data}

The related teachers of National Costumes Museum provided the images and text.

\section{Sketchup modelling software was used to model the national costume museum}

SketchUp is a 3D design software which is very popular and easy to use. Even a large number of 3D scenes of Google maps come from the SketchUp.

Using SketchUp to model the room is relatively simple. We can extrude to make the room form the internal space using the basic geometric model. The walls of the room is texture mapped using the material editor. For dress exhibits in the museum, first the collections are photographed, usually professional equipment is used to scan the collections to get the texture data. Then the texture wall is given by those texture data. In the detailed operation process it need two times texture operation: first texture wall are divided into many regions according to the picture size .The purpose of dong this is that it has many image in a wall. It is shown in Figure 2. The second time we need add picture and rationally adjust the position to achieve good texture display effect.

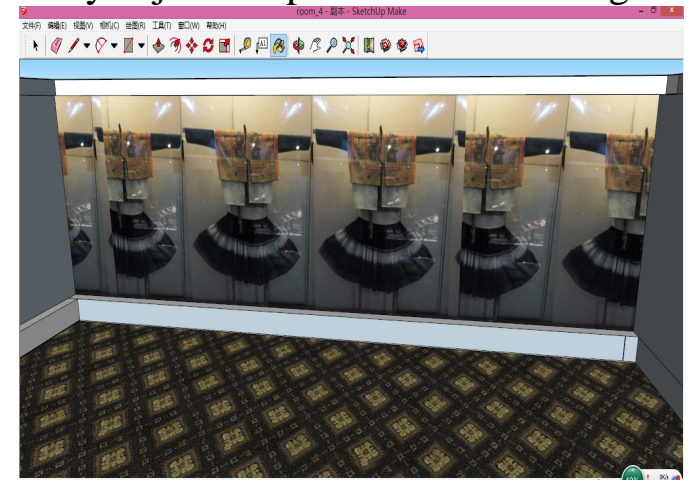

Figure 2 wall are divided into many regions

\section{Texture import and animation production}

The model using SketchUp software to build is imported to 3dsmax in order to Baking map. The SketchUp file export format should be set for $* 3 \mathrm{ds}$, which has better compatible. In the actual operation, when the $* 3 \mathrm{ds}$ SketchUp model will be exported to $3 \mathrm{ds}$ Max, the texture is lost. Change path will be the main reason for this problem. The compatibility of the two software exists some 
problems. When sketchUp gives wall texture into 3ds Max software, 3ds Max cannot find the right texture mapping. There are two ways to solve: 1 . The SketchUp model is partial exported, such as the first time export the same texture of the exterior surface, so that 3ds Max only have wall model, this model has not texture effect. We need to use object picking up material from the material editor to texture, wall material was extracted, then in the map to find the diffuse colour, click it and will pop up bitmap options, then choice the bitmap address repositioning and show standard map in the viewport .then the texture will show on the wall. 2. The SketchUp model is also partial exported and is saved as *.max format, wall material was extracted in the material pickup, then choice "show standard map in the viewport", texture will be re imported.

The virtual National Costume Museum of roaming video are created in the SketchUp by adding animation frames and making the animation frame continuous play. The generation of roaming path in SketchUp is automatically generated according to the position of two animation frames. If you want to get a good result, you need to add a lot of animation frames to adjust the route.

\section{3ds Max rendering}

The texture of the dress pictures are exhibited on the wall in 3ds Max and SketchUp. However, virtual reality software (VRP) does not support custom textures, so in 3ds Max the clothing texture are baked into maps and made into a wall of "material shell ", which can displayed properly when imported to VRP software.

Using 3ds Max for baking, shaded walls cannot be displayed ,the solution is to add light rendering before the model is baked, which will make the shadow under a lighting .Baking effect is showed in Figure 3.

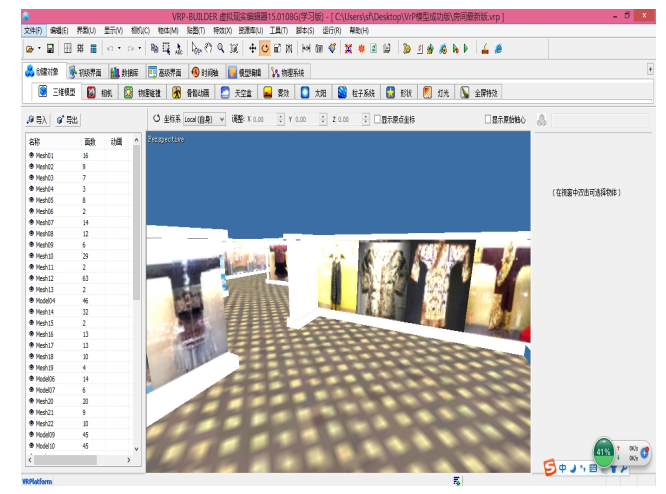

Figure 3 the shaded walls can be seen using light rendering

\section{VRP roaming system}

In VRP software, you can use the "sky box" to beautify the external background of the model. Making roaming system, the first step is to select the role of skeletal model, in the action library action is added and is set as the default action .The action name should be named in English, then the keyboard can control the behaviour of the role. Then add the role control camera, bind the selected role model, as showed in figure 4; then create new function in the script editor, add music directory, finally open model impact test system, Increase the roaming sense of reality . 


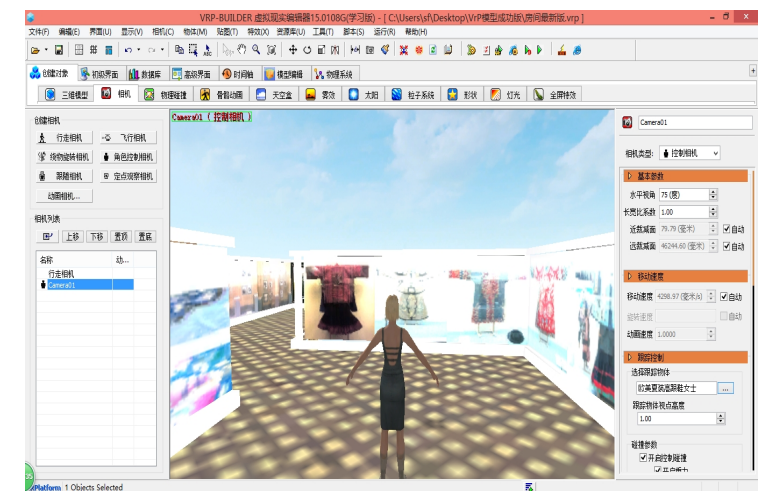

Figure 4 select role skeleton model

\section{Summary}

In this paper Google SketchUp software was used to model the national costume museum, then the model was put into 3 ds Max model, lighting rendering, virtual reality software VPR is used to create the roaming system. The virtual national costumes museum of Beijing institute of fashion clothing is created. In the roaming system, the user use the mouse and keyboard to realize the virtual scene roaming, browse the scene and real-time change the path according to individual operation.

\section{Acknowledgement}

This paper got the support by "digital and interactive media, Beijing municipal key laboratory", the project Number is KF2014-05. "the key scientific research project, Beijing institute of fashion technology ", the project number is 131201990107/004, the Beijing municipal education commission project, the project Number is KYJH02140201/021

\section{Reference}

1. Zhuang Chunhua, Wang Pu. Virtual reality technology and its application [M]. Beijing: Electronic Industry Press, $12 \sim 2010.1$

2. Li Qian. Application Research of virtual reality technology in virtual campus roaming system (D) Zhejiang: Zhejiang University of Technology, 2012 